\title{
EFFICACY, TOOTH SURFACE MICROHARDNESS AND ROUGHNESS AFTER TREATMENT WITH COMBINATION OF LASER AND HOME BLEACHING PROTOCOL: AN IN VITRO STUDY
}

\begin{abstract}
Teeth whitening or bleaching has pleased people with aesthetic concerns for long. To improve the efficacy of bleaching and reduce the ill effects on the tooth surface, a combination of power bleaching (PB) and home bleaching (HB) can be used.
\end{abstract}

Objective: To compare the efficacy and effects of combinations of $\mathrm{PB} /$ laser bleaching (LB) and $\mathrm{HB}$ protocol on human natural tooth structure.

Materials and methods: Eighty-eight permanent maxillary central incisors were randomly divided into four groups $(n=22)$. After staining, teeth were bleached using different bleaching protocols: Group 0 (control), Group 1 (Laser White 20 46\% hydrogen peroxide (HP) + Opalescence PF 20\% carbamide peroxide (CP) - HB sequence for 3 days), Group 2 (Laser White $2046 \%$ HP + Opalescence PF 20\% CP - HB sequence for 7 days), Group 3 (Opalescence PF 20\% CP HB sequence for 14 days). Colorimetric measurement was performed, enamel surface roughness and microhardness were measured. Scanning Electron microscope (SEM) evaluation was done to compare the surface topography. Pre and post bleaching data were analysed using paired $T$-test. Multiple comparison between groups was carried out using one-way ANOVA complemented by Post hoc test (Bonferroni), with significance level set at $\mathrm{P}<0.05$.

Results: All protocols demonstrated significant efficacy to whiten stained enamel. All groups demonstrated significant increase in hardness $(\mathrm{P}<0.05)$. Surface roughness reduced significantly in Group 1 and 2. SEM showed that Group 1 had a similar microscopic surface appearance as unbleached enamel, while Group 3 had accentuated irregularities.

Conclusions: LB followed by HB for 3 days is the most effective in whitening stained teeth with positive effects on tooth surface hardness while maintaining surface topography of dental hard tissues.

Keywords: Home bleaching, Laser bleaching, Combination bleaching, Teeth whitening, tooth surface hardness.

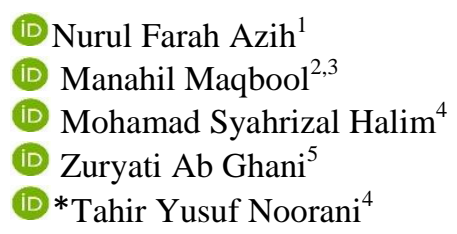

ORCID IDs of the authors:

N.F.A. $\quad$ 0000-0001-6065-1794

M.M. 0000-0002-2203-1882

M.S.H. 0000-0002-0423-8070

Z.A.G. 0000-0002-7923-9414

T.Y.N. 0000-0002-4661-7458

\footnotetext{
${ }^{1}$ Klinik Pergigian Jalan Gambut, Ministry of Health Malaysia.

${ }^{2}$ Paediatric Dentistry Unit, School of Dental Sciences, Universiti Sains Malaysia, Health campus, 16150 Kubang Kerian, Kota Bharu, Kelantan, Malaysia.

${ }^{3}$ Department of Paediatric Dentistry, Rashid Latif Dental College, Rashid Latif Medical College, Lahore, Pakistan.

${ }^{4}$ Conservative Dentistry Unit, School of Dental Sciences, Universiti Sains Malaysia, Health campus, 16150 Kubang Kerian, Kota Bharu, Kelantan, Malaysia.

5 Prosthodontic Unit, School of Dental Sciences, Universiti Sains Malaysia, Health campus, 16150 Kubang Kerian, Kota Bharu, Kelantan, Malaysia.
}

Received : 04.05.2021

Accepted : 29.11 .2021

How to Cite Azih NF, Maqbool M, Halim MS, Noorani TY, Ab Ghani Z. Efficacy, Tooth Surface Microhardness and Roughness After Treatment with Combination of Laser and Home Bleaching Protocol: An In Vitro Study. Cumhuriyet Dent J 2021;24:4:427-441.

*Corresponding Author:

Conservative Dentistry Unit, School of Dental Sciences, Universiti Sains Malaysia, Health campus, 16150 Kubang Kerian, Kota Bharu, Kelantan, Malaysia.

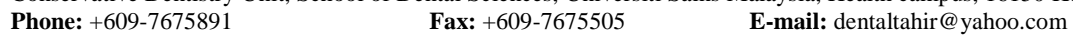




\section{INTRODUCTION}

Vital tooth bleaching or whitening has gained popularity in recent years, to fulfil patient demands for health and aesthetics. ${ }^{1}$ A study assessing the impact of teeth on personal aesthetic satisfaction found that dental variables (including tooth colour) were more important than orthodontic variables, suggesting that appearance of the teeth was a greater contributing factor to an aesthetic smile than their position within an arch. ${ }^{2}$ Several methods have been described in the literature for improving dental aesthetics. However, the bleaching technique is widely used because of its ease, effectiveness ${ }^{3}$, non-invasive nature and affordability for treating discoloured teeth when compared to veneers and crowns. ${ }^{4,5}$

There are three well-known techniques of vital tooth bleaching: professionally supervised nightguard (home) bleaching, in-office or PB and over the counter bleaching products. ${ }^{6}$ A successful HB technique was first described by Klusmies in 1968 however, it received worldwide acceptance when it was described by Haywood and Heymann in $1989 .^{7-9}$

In office bleaching involves the use of HP $(30-35 \%)^{10}$ as bleaching solution, with or without light activation to treat severely discoloured or difficult bleaching cases to produce immediate results. ${ }^{11}$ A further modification to the PB system was the use of an argon laser and a variety of light sources. ${ }^{10,12} \mathrm{~PB}$ was frequently combined with $\mathrm{HB}$ systems to maximize the bleaching effect and give a kick start to the whitening procedure before the patient continued with nightguard vital bleaching at home. ${ }^{13}$ Generally, the efficacy of LB and HB are approximately the same when compared at providing effective tooth whitening. ${ }^{4}$

Several studies have been carried out to measure the microhardness of enamel and dentine after application of short regimes of $10-22 \%$ of carbamide peroxide. They have found that it does not significantly alter the hardness. ${ }^{14-17}$ It was suggested that an increase in enamel erosion caused by bleaching treatment may facilitate fluoride penetration and consequently result in rehardening the enamel after bleaching. ${ }^{18,19}$
Most studies concentrate on comparing the effectiveness of various bleaching agents, that is, either comparing their concentration or the method of practical application and duration of application to prove the most reliable product that can give the best aesthetic result with minimal side effects on the tooth. ${ }^{20-23}$ However, the results are still inconclusive with regards to the efficacy and effects of treatment with various bleaching agents. To the best of our knowledge, there is no previous study that has compared the combination of LB and HB over a period of different days. Thus, to take advantages of the efficacy of home bleaching and reduce its ill-effects on the tooth surface, a combination of LB and HB can be used. Hence, the purpose of this study was to investigate and determine whether the combination of LB and HB treatment will give an optimal result while minimizing the ill-effects on dental hard tissues.

To the best of our knowledge, no study has been carried out to determine the effectiveness and effects on the enamel surface after laser and home bleaching combination treatment. Thus, this study will assess the efficacy of a combination of laser and home bleaching treatment and its effects on microhardness, roughness and morphological changes on the enamel surface. The results of this study will serve as a basis for determining whether the use of a combination of laser and home bleaching can help in achieving optimum bleaching efficacy while causing minimum illeffects to the tooth structure.

The null hypotheses tested were, that there was no significant difference in colour changes of teeth, microhardness of teeth, enamel surface roughness, and enamel surface morphology after treatment with combinations of laser bleaching and different durations of home bleaching protocol.

\section{MATERIALS AND METHODS}

Eighty-eight permanent maxillary central incisors were collected based on inclusion and exclusion criteria. Sound human permanent maxillary central incisors extracted due to periodontal problems and other reasons, were included, whereas a tooth that had caries, cracks, fracture, or restorations, were excluded from this study. 
The teeth were kept in saturated thymol solution until preparation for testing. Human blood that was used for staining teeth was obtained from Hospital Universiti Sains Malaysia blood bank, which had been heparinized to avoid coagulation. The ethical approval for conducting this study was obtained from the Human Research Ethics Committee of Universiti Sains Malaysia (JEPem code: USM/JEPem/17050252).

\section{Specimen Preparation}

The collected teeth were cleaned with pumice and prophylaxis brush to remove any debris and stains. The cleaned teeth were stored in chlorhexidine solution to avoid dehydration. The roots were cut $1 \mathrm{~mm}$ below the cementoenamel junction. Each tooth was embedded in self-cure acrylic resin with the enamel surface facing the mould base. The enamel surface was then exposed by trimming acrylic with an acrylic bur. Each specimen had a surface area of $14 \mathrm{~mm} \times 8 \mathrm{~mm}$ $( \pm 1 \mathrm{~mm})^{7}$

\section{Staining Procedure}

Enamel of specimens were etched with $37 \%$ phosphoric acid for 15 seconds to remove the smear layer. Human blood that was obtained from the blood bank was used to stain the specimens. The blood was centrifuged at $10,000 \mathrm{rpm}$ for 10 mins and the serum discarded. Then, $40 \mathrm{~mL}$ of distilled water was added to $60 \mathrm{~mL}$ of the precipitated blood and this mixture was centrifuged at 10,000 rpm for 20 mins. The teeth specimens were immersed in this solution for 4 days, where a centrifugation cycle of $10,000 \mathrm{rpm}$ for 20 mins was performed at every 24 hours. After 4 days, the specimens were removed, washed with distilled water, dried with absorbent paper and kept in an incubator at $37^{\circ} \mathrm{C}$ at $100 \%$ relative humidity for 15 days. ${ }^{7}$ The Sanyo MIR 253 Cooled Incubator (Sanya, MA, USA) was used. It has the following specifications: provides large capacity, accurately controlled environment over a wide range of temperatures. This refrigerated incubator has a temperature range between $-10^{\circ} \mathrm{C}$ to $+50^{\circ} \mathrm{C}$, controlled from the keypad interface with digital screen set at the top of the instrument. From this control panel users can set their desired temperature, activate auto defrost, set and silence alarms, and define up to 3 programs each with up to 99 steps. Users of this Sanyo Incubator can choose to repeat their program multiple times, up to 99 , set their independent high/low temperature limit, and choose their duration up to 99.5 hours. This cooling incubator is upright with a brightly lit, $9 \mathrm{cu} \mathrm{ft}$ interior, with fan circulation and adjustable wire shelving, lined with easy to clean stainless steel.

\section{Bleaching Treatment}

After staining, the specimens were randomly assigned to four different groups ( $\mathrm{n}=22)$; Group 0 (Staining with no bleaching - control), Group 1 (Laser White 20 46\% HP + Opalescence PF 20\% CP - HB sequence for 3 days), Group 2 (Laser White $2046 \%$ HP + Opalescence PF 20\% CP HB sequence for 7 days), Group 3 (Opalescence PF 20\% CP - HB sequence for 14 days). The samples were dried with cotton wool pellets and care was taken to not let the specimen desiccate.

For Group 1, a thin layer of Laser White 46\% HP (Biolase Technology, CA, USA) whitening gel was applied all over the exposed tooth surface evenly with a brush applicator tip to about $1 \mathrm{~mm}$ thickness. The Ezlase 810nm system was prepared and laser-activated. The whitening handpiece was held in place near $(\sim 1 \mathrm{~mm})$ to the tooth surface coated with bleaching material for the duration of laser delivery (200 J or approximately 30 seconds). The Ezlase $810 \mathrm{~nm}$ system was allowed to rest for one (1) minute and the tooth was exposed to laser irradiation for the second time as per the manufacturer's instructions. The gel was then allowed to remain on the teeth for a minimum of 5 minutes after the second laser cycle. The gel was then removed using high-speed suction and flushed with an air and water spray to remove any residual gel. For the next 3 days, the Opalescence PF 20\% CP (Ultradent Co., South Jordan, UT, USA) was used according to the manufacturer's instruction where the exposed teeth surfaces were covered by a layer of $1 \mathrm{~mm}$ of the whitening gel for two hours daily in a humid atmosphere at $37^{\circ} \mathrm{C}$. The specimens were stored in artificial saliva, in an incubator at $37^{\circ} \mathrm{C}$ with $100 \%$ relative humidity in between the $\mathrm{HB}$ treatments. The artificial saliva was replaced daily. 
The teeth in group 2 were also bleached following the procedure described in group 1, however, the Opalescence PF 20\% CP (Ultradent Co., South Jordan, UT, USA) was applied for 7 days.

In Group 3, only Opalescence PF 20\% CP (Ultradent Co., South Jordan, UT, USA) was applied for 14 days following the procedure as described for Group 1.
Colorimetric measurement, surface hardness and surface roughness on sample surfaces were taken before (baseline) and after the application of bleaching agent in each group. Each measurement was taken three times for each sample before and three times after the application of the bleaching agent. Contents and properties of the two bleaching systems can be seen in table 1 . Specifications of the Biolase diode laser system can be seen in table 2 .

Table 1: Contents and properties of bleaching systems used in this study

\title{
BLEACHING SYSTEMS \\ Laser White $2046 \%$ HP \\ Opalescence PF 20\% CP - HB
}

1. LaserWhite 20 is a proprietary dental whitening gel used in conjunction with a BIOLASE diode laser system.

2. The laser, through a specialized handpiece and delivery system, activates the LaserWhite20 whitening gel to accelerate the whitening process. 3. The Base Gel contains a $45 \%$ concentrated hydrogen peroxide as an active ingredient.

PROPERTIES 4. The Activator is formulated with a proprietary dye that activates by absorbing laser energy in the specific BIOLASE diode laser system wavelengths.

5. The unique mixing syringe system ensures freshness for each application and precise dosing of the activator.

6. When mixed, the LaserWhite 20 whitening gel results in a $35 \%$ hydrogen peroxide.

1. LaserWhite 20 whitening gel

CONTENTS

2. Base Gel

3. Activator

4. BIOLASE diode laser
1. This system is intended to be dentistsupplied and supervised.

2. The whitening agents are clear, flavoured, high-viscosity, sticky, peroxide containing gels.

3. The agents are available in $10 \%, 15 \%$, and $20 \%$ carbamide peroxide, and in $35 \%$ and $45 \%$ carbamide peroxide equivalent gels.

4. Opalescence whitening take home products feature sustained release action and adhesive properties.

5. All Opalescence whitening products are gluten-free and kosher.

6. The increase in microhardness is due to potassium nitrate and sodium fluoride.

7. They also contain significant water content to help prevent tooth dehydration and shade relapse.

1. Whitening agents (e.g. carbamide peroxide containing gels)

2. Potassium Nitrate

3. Sodium Fluoride

4. Water

Table 2: Specifications of Biolase Diode Laser System

\section{BIOLASE DIODE LASER SYSTEM}

\begin{tabular}{l}
\hline GENERAL \\
Frequency \\
External Fuses \\
Weight \\
Dimensions \\
W x H x D \\
ELECTRICAL \\
Operating Voltage \\
Main Control Power Switch \\
Remote Interruption \\
LASER \\
Laser Classification \\
Medium \\
Wavelength \\
Max Output Power \\
Power Accuracy \\
\hline
\end{tabular}

\author{
$50 / 60 \mathrm{~Hz}$ \\ None \\ 2 lbs. (1.0 kg) \\ $(3.5 ” \times 7.0 ” \times 2.5 ”)(8.5 \times 18 \times 6 \mathrm{~cm})$
}

100 to $240 \sim$ at $2 \mathrm{~A}$

On / Off Controls Keypad Button, Emergency Stop

Remote Interlock Connector

IV (4)

GaAlAs, InGaAsP

$810 \pm 15 \mathrm{~nm}$ or $940 \pm 15 \mathrm{~nm}$

7 Watts@940nm,4.5 Watts @ 810nm $\pm 20 \%$ 


\begin{tabular}{ll}
\hline Power Modes & Continuous, Pulse Modulation \\
Pulse Length & $0.06 \mathrm{~ms}-10 \mathrm{sec}$ \\
Pulse Interval & $0.06 \mathrm{~ms}-10 \mathrm{sec}$ \\
Pulse Repetition & Rate up to $10 \mathrm{KHz}$ \\
Fiber Tips Diameter & $200,300,400 \mu \mathrm{m}$ \\
NOHD & 11.8 meters \\
Beam Divergence & $8-22$ degrees per side angle \\
Fiber Cable Length & 5 feet $(1.524$ meters $)$ \\
OTHER LIGHT SOURCES & max $3 \mathrm{~mW}, 630-670 \mathrm{~nm}$, class 3B \\
Aiming Beam Laser Diode &
\end{tabular}

\section{Colorimetric Measurement}

Colorimetric measurements were done using Vita Easy Shade ${ }^{\circledR}$ Advance 4.0 (VITA Zahnfabrik, Bad Säckingen, Germany) on sample surfaces before (baseline) and after the application of bleaching agent in each group. Calibration was done on Vita Easy Shade followed manufacturer instructions before measurement was performed. Calibration was repeated after every 5 samples. The measurements were taken three times for each sample before and three times after the application of the bleaching agent). Then their mean was calculated and recorded. ${ }^{4}$ The colour difference was calculated using the formula.

$$
\Delta E=\left[(\Delta L)^{2}+(\Delta a)^{2}+(\Delta b)^{2}\right] 1 / 2,
$$

$$
\Delta \mathrm{L}=\text { final } \mathrm{L} \text {-initial } \mathrm{L}, \Delta \mathrm{a}=\text { final a-initial } \mathrm{a}, \Delta \mathrm{b}=\text { final } \mathrm{b} \text {-initial } \mathrm{b}
$$

Even though the room lighting did not have an effect on measurements, since the $4^{\text {th }}$ generation Vita Easy Shade ${ }^{\circledR}$ was utilized which has its own built-in light, but still the measurements were performed in a room with bright day light and a black background. The time of the day was fixed for taking all measurements to ensure standardization. A black coloured matte cardboard sheet was used as a background to avoid scattering of the light and shadowing. Since the colour black absorbs all the incoming light, so its' use is advantageous, as it helps in producing clear and shadowless images. ${ }^{49}$ Colour recordings were performed by one experienced clinician using a Vita Easyshade Advance 4.0 spectrophotometer (Vita Zahnfabrik, Bad Säckingen, Germany) according to the manufacturer's instructions. This digital shade matching device uses a D-65 illumination. In order to mimic a standardized daylight, all measurements were performed in a room, which was exposed to daylight conditions. ${ }^{47}$

As per manufacturer's details for Vita Easy Shade ( ${ }^{\circledR}$ Advance 4.0 (Vita Zahnfabrik, Bad Säckingen, Germany), it is the 4th generation electronic shade taking device, which is ideal as it ensures fast, reliable and objective tooth shade determination. In a matter of seconds, this device allows you to determine and verify all tooth shades based on the internationally renowned tooth shade standards VITA classical A1 - D4 and VITA SYSTEM 3D-MASTER. The device is accurate as the human eye, and is equipped with its own light source so that daylight is no longer a relevant factor. Further technical details for Vita Easy Shade ${ }^{\circledR}$ Advance 4.0, can be seen in table 3. 
Table 3: Technical data for Vita Easy Shade ${ }^{\circledR}$ Advance 4.0

Vita Easyshade Advance 4.0 ${ }^{\circledR}$

Technical data

1. Spectrophotometer, measurement range $400-700 \mathrm{~nm}$.

2. Inductive charging concept with long-life AA batteries.

3. Output of all tooth shades in the established standard shade systems VITA classical A1-D4 and VITA SYSTEM 3D-MASTER, as well as indication of the VITABLOCS shades and bleached index, in accordance with the American Dental Association.

4. Display of lab and LCh values.

5. Bluetooth interface for wireless communication with the VITA Assist PC software and VITA mobileAssist app.

6. Reliable and economical, thanks to precise tooth shade information in the VITA shade standards for reliable shade reproduction and reduced shade corrections.

7. Simple and intuitive, thanks to the easy-to-use touchscreen and software.

8. Efficient, digital communication for exchanging information about tooth shade and images between the dental practice and the laboratory.

\section{Microhardness Testing}

Each specimen was divided into two surface area using pencil subjected to indentation before and after bleaching treatment. Specimens were positioned perpendicularly to the long axis of the indentor for 15 seconds to record the Vickers hardness number (VHN). A $5 \mathrm{~kg}$ load Vickers indentor (Future Tech, Tokyo, Japan) attached to a hardness tester (VM-50, Fuel Instruments, and Engineers, Maharashtra, India) was used. Their mean values were calculated and recorded. ${ }^{24}$

\section{Surface Roughness Testing}

A profilometer (Surface Texture Measuring Instrument - Surfcom Flex 50A, Tokyo Seimitsu Co., Ltd, Japan) was used to measure the surface roughness. The resolution for this device was $0.00016 \mu \mathrm{m} / \pm 4 \mu \mathrm{m}$ to $0.016 \mu \mathrm{m} / \pm 400 \mu \mathrm{m}$. The measuring range was $400 \mu \mathrm{m}$ vertically and 50 $\mathrm{mm}$ horizontally. This procedure was done according to the manufacturer's instructions. Each specimen was positioned on a flat surface where the pickup of the profilometer came in contact with the pattern on the calibration side of the specimen. The stylus was then applied and the meter was run at the evaluation length of $7 \mathrm{~mm}$ at a measured speed of $0.15 \mathrm{~mm} / \mathrm{s}$. Three (3) measurements were taken and their mean values were calculated and recorded. ${ }^{24}$

\section{Morphological changes evaluation}

Two samples from each group were selected randomly for morphological evaluation using scanning electron microscope (SEM) (FEI QuantaTM 450 FEG, ThermoFisher Scientific, Oregon, USA). The specimen was gently airdried, dehydrated with alcohol and then dried at the critical point (a method used to minimize specimen distortion due to drying tensions). The samples were then sputter-coated with goldpalladium and examined under a SEM. Serial SEM microphotographs of the surface of each specimen at $5,000 \mathrm{X}$ and $10,000 \mathrm{X}$ original magnification were obtained to evaluate enamel texture changes. The surface morphology of enamel in each picture was examined by two operator compared and determine whether any difference in the enamel texture could be seen after different treatment modalities. ${ }^{25}$

\section{Statistical Analysis}

Data collected were analysed using SPSS version 26.0. Data for colour changes, hardness testing, and surface roughness pre and post bleaching were analyzed using paired T-test. Multiple comparison between groups was carried out using one-way ANOVA complemented by Post Hoc (Bonferroni procedure). The level of significance was set at $\mathrm{P}=0.05$. 


\section{RESULTS}

\section{Colour changes}

Table 4 and 5 show the mean colour changes of human tooth post bleaching procedure with three different bleaching protocols. Paired t-test revealed that there were significant changes in all treatment groups except the control group. Oneway ANOVA test showed that there was a significant difference in the color changes when the comparison was made between groups with $\mathrm{p}$ $<0.05$. Furthermore, posthoc Benferroni analysis revealed that colour changes produced by a combination of laser and $\mathrm{HB}$ were superior compared to HB alone $(p<0.05)$. However, there was no significant difference in colour changes between both groups of laser and HB combination $(\mathrm{p}>0.05)$ (Table 6).

Table 4: Colorimetric reading before and after using combination of laser and home bleaching protocol

\begin{tabular}{|c|c|c|c|c|c|c|c|c|c|}
\hline \multirow{2}{*}{ Groups } & \multirow{2}{*}{$\mathbf{N}$} & \multicolumn{3}{|c|}{ Before bleaching } & \multicolumn{3}{|c|}{ Post-bleaching } & \multirow{2}{*}{$\begin{array}{c}\Delta \mathrm{E} \text { Mean } \\
\text { difference }(\mathrm{SD})\end{array}$} & \multirow{2}{*}{$\begin{array}{c}p \text { - } \\
\text { value }\end{array}$} \\
\hline & & $\mathbf{L}^{*}$ & $\mathbf{a}^{*}$ & $\mathbf{b}^{*}$ & $\mathbf{L}^{*}$ & $a^{*}$ & $\mathbf{b}^{*}$ & & \\
\hline Control & 22 & 52.96 & 7.75 & 37.89 & 61.70 & 6.62 & 43.00 & $\begin{array}{c}11.10 \\
(4.481)\end{array}$ & 0.068 \\
\hline $\begin{array}{l}\mathrm{LB}+\mathrm{HB} \\
3 \text { days }\end{array}$ & 22 & 59.54 & 7.29 & 36.43 & 89.30 & -0.81 & 28.41 & $\begin{array}{c}32.06 \\
(3.459)\end{array}$ & $0.001 *$ \\
\hline $\begin{array}{l}\mathrm{LB}+\mathrm{HB} \\
7 \text { days }\end{array}$ & 22 & 58.05 & 5.78 & 34.31 & 89.70 & -0.08 & 28.01 & $\begin{array}{c}33.12 \\
(6.191)\end{array}$ & $0.001 *$ \\
\hline HB 14 days & 22 & 66.26 & 4.57 & 32.65 & 90.81 & -0.19 & 28.53 & $\begin{array}{c}25.82 \\
(5.825)\end{array}$ & $0.001 *$ \\
\hline
\end{tabular}

Table 5: The comparison of colour changes $(\Delta \mathrm{E})$ after using combination of laser and home bleaching protocol

\begin{tabular}{llccc}
\hline Groups & $\mathbf{N}$ & $\begin{array}{c}\Delta \mathbf{E} \\
\text { Mean }(\text { SD) }\end{array}$ & F statistic $^{\mathbf{a}}(\mathbf{d f})$ & $\boldsymbol{p}^{\text {-value }}$ st $^{\mathbf{b}}$ \\
\hline Control & 22 & $11.10(4.481)$ & $86.75(3)$ & $<\mathbf{0 . 0 0 1 *}$ \\
LB + HB 3days & 22 & $32.06(3.459)$ & \\
LB + HB 7days & 22 & $33.12(6.191)$ & \\
HB 14 days & 22 & $25.82(5.825)$ & \\
\hline
\end{tabular}

${ }^{\mathrm{a}}$ ANOVA test *statistically significant $p<0.05$

${ }^{\mathrm{b}}$ the mean score with significant $\mathrm{P}=$ value were tested for multiple comparisons using Post hoc test (Bonferroni)

Table 6: Multiple comparisons of colour changes $(\Delta E)$ after bleaching regime between groups $(n=88)$

\begin{tabular}{llcc}
\hline Between groups & & Mean difference $(\mathbf{9 5 \%}$ CI $)$ & $\boldsymbol{p}$-value \\
\hline Control & LB+ HB 3days & $-20.96(-25.120,-16.800)$ & $<\mathbf{0 . 0 0 1 *}$ \\
Control & LB + HB 7days & $-22.01(-26.173,-17.852)$ & $<\mathbf{0 . 0 0 1 *}$ \\
Control & HB 14 days & $-14.71(-18.874,-10.554)$ & $<\mathbf{0 . 0 0 1 *}$ \\
LB+ HB 3days & LB + HB 7days & $-1.05(-5.213,3.108)$ & 1.000 \\
LB + HB 3days & HB 14days & $6.25(2.086,10.406)$ & $\mathbf{0 . 0 0 1 *}$ \\
LB + HB 7days & HB 14days & $7.30(3.139,11.459)$ & $<\mathbf{0 . 0 0 1 *}$ \\
\hline
\end{tabular}

Post hoc test (Bonferroni); *statistically significant $p<0.05$

\section{Hardness Test}

Table 7 shows that there was a significant change in surface hardness (VHN) before and after bleaching protocols in all treatment groups. Meanwhile Table 8, ANOVA test demonstrated that all treatments group had a significant increase in hardness as compared to control. However, no significant difference was noted among treatment groups $(\mathrm{P}>0.05)$, as depicted in Table 9. 
Table 7: The comparison of surface hardness (VHN) before and after bleaching with combination of laser and home bleaching protocol

\begin{tabular}{|c|c|c|c|c|c|c|}
\hline Groups & $\mathbf{n}$ & $\begin{array}{c}\text { Pre-bleaching } \\
\text { Mean (SD) }\end{array}$ & $\begin{array}{c}\text { Post-bleaching } \\
\text { Mean (SD) }\end{array}$ & $\begin{array}{c}\text { Mean difference }(95 \% \\
\text { CI })\end{array}$ & $\begin{array}{c}t \text {-statistics } \\
\text { (df) }\end{array}$ & $p$-value \\
\hline Control & 22 & $320.23(33.242)$ & $296.86(51.911)$ & $\begin{array}{c}23.36 \\
(-1.643,48.370)\end{array}$ & $1.943(21)$ & 0.066 \\
\hline $\begin{array}{l}\mathrm{LB}+\mathrm{HB} 3 \\
\text { days }\end{array}$ & 22 & $310.41(31.367)$ & $413.23(35.232)$ & $\begin{array}{c}-102.82 \\
(-120.258,-85.378)\end{array}$ & $-12.260(21)$ & $<0.001$ \\
\hline $\begin{array}{l}\mathrm{LB}+\mathrm{HB} 7 \\
\text { days }\end{array}$ & 22 & $299.86(33.901)$ & $415.18(38.575)$ & $\begin{array}{c}-115.32 \\
(-134.780,-95.856)\end{array}$ & $-12.322(21)$ & $<0.001$ \\
\hline HB 14 days & 22 & $311.05(27.825)$ & $423.32(18.334)$ & $\begin{array}{c}-112.27 \\
(-126.251,-98.294) \\
\end{array}$ & $-16.703(21)$ & $<0.001$ \\
\hline
\end{tabular}

Table 8: The comparison of change in surface hardness (VHN) after bleaching with combination of laser and home bleaching protocol

\begin{tabular}{|c|c|c|c|c|}
\hline Groups & $\mathbf{N}$ & $\begin{array}{c}\text { VHN } \\
\text { Mean (SD) }\end{array}$ & F statistic ${ }^{\mathrm{s}}$ (df) & $p$-value ${ }^{b}$ \\
\hline Control & 22 & $46.09(39.081)$ & $15.467(3)$ & $<0.001 *$ \\
\hline $\begin{array}{l}\mathrm{LB}+\mathrm{HB} \\
3 \text { days }\end{array}$ & 22 & $102.82(39.335)$ & & \\
\hline $\begin{array}{l}\mathrm{LB}+\mathrm{HB} \\
7 \text { days }\end{array}$ & 22 & $115.32(43.895)$ & & \\
\hline HB 14 days & 22 & $112.27(31.528)$ & & \\
\hline
\end{tabular}

${ }^{\mathrm{a}}$ ANOVA test $*$ statistically significant $p<0.05$

${ }^{\mathrm{b}}$ the mean score with significant $\mathrm{P}=$ value will be tested multiple comparison Post hoc test (Bonferroni)

Table 9: Multiple comparisons of microhardness differences after bleaching regime between groups (N=88)

\begin{tabular}{lccc}
\hline & Between groups & Mean difference (95\% CI) & $\boldsymbol{p}$-value \\
\hline Control & LB + HB 3 days & $-56.73(-88.270,-25.185)$ & $\mathbf{0 . 0 0 1 *}$ \\
Control & LB + HB 7 days & $-69.23(-100.77,-37.685)$ & $<\mathbf{< . 0 0 1 *}$ \\
Control & HB 14 days & $-66.18(-97.724,-34.640)$ & $<\mathbf{0 . 0 0 1 *}$ \\
LB + HB 3 days & LB + HB 7 days & $-12.50(-44.042,19.042)$ & 1.000 \\
LB + HB 3 days & HB 14 days & $-9.45(-40.997,22.088)$ & 1.000 \\
LB + HB 7 days & HB 14 days & $3.05(-28.497,34.588)$ & 1.000 \\
\hline
\end{tabular}

Post hoc test (Bonferroni procedure); *statistically significant $p<0.05$

\section{Surface roughness}

Table 10 shows that there was a significant reduction in surface roughness after treatment with combination bleaching procedures while there was no significant change with $\mathrm{HB}$ alone.
Table 11 and 12 shows a significant difference in surface roughness change in LB + HB 3 days and $\mathrm{HB}$ groups as compared to the control but no significant difference between treatment groups.

Table 10: The comparison of surface roughness $(\mathrm{Ra})$ before and after bleaching in each group

\begin{tabular}{|c|c|c|c|c|c|c|}
\hline Groups & $\mathbf{n}$ & $\begin{array}{l}\text { Pre-bleaching } \\
\text { Mean (SD) }\end{array}$ & $\begin{array}{l}\text { Post-bleaching } \\
\text { Mean (SD) }\end{array}$ & $\begin{array}{c}\text { Mean difference }(95 \% \\
\text { CI })\end{array}$ & $\begin{array}{l}\text { t-statistics } \\
\text { (df) }\end{array}$ & $p$-value \\
\hline Control & 22 & $2.18(0.587)$ & $2.49(0.703)$ & $-0.31(-0.593,-0.027)$ & $-2.277(21)$ & 0.033* \\
\hline LB+ HB 3days & 22 & $2.51(0.506)$ & $2.35(0.430)$ & $0.16(0.018,0.299)$ & $2.349(21)$ & 0.029* \\
\hline LB+ HB 7days & 22 & $3.04(0.657)$ & $2.71(0.421)$ & $0.32(0.129,0.520)$ & $3.448(21)$ & $0.002 *$ \\
\hline HB 14 days & 22 & $2.53(0.565)$ & $2.41(0.433)$ & $0.12(-0.100,0.335)$ & $1.121(21)$ & 0.275 \\
\hline
\end{tabular}


Table 11: The comparison of change in surface roughness $(\mu \mathrm{m})$ after bleaching with combination of laser and home bleaching protocol

\begin{tabular}{|c|c|c|c|c|c|}
\hline Groups & $\mathbf{n}$ & $\begin{array}{c}\text { Roughness differences } \\
\text { Mean (SD) }\end{array}$ & MS & F Statistics $^{\text {a }}(\mathbf{d f})$ & $p$-value ${ }^{b}$ \\
\hline Control & 22 & $0.59(0.373)$ & \multirow{4}{*}{0.452} & \multirow{4}{*}{$3.592(3)$} & \multirow{4}{*}{$0.017 *$} \\
\hline LB+ HB 3days & 22 & $0.28(0.207)$ & & & \\
\hline LB+ HB 7days & 22 & $0.04(0.398)$ & & & \\
\hline HB 14 days & 22 & $0.01(0.403)$ & & & \\
\hline
\end{tabular}

\begin{tabular}{lccc}
\hline & Between groups & Mean difference (95\% CI) & $\boldsymbol{p}$-value \\
\hline Control & LB+ HB 3days & $0.31(0.021,0.599)$ & $\mathbf{0 . 0 2 9} *$ \\
Control & LB+ HB 7days & $0.22(-0.069,0.509)$ & 0.257 \\
Control & HB 14 days & $0.30(0.008,0.585)$ & $\mathbf{0 . 0 4 1 *}$ \\
LB+ HB 3days & LB+ HB 7days & $-0.09(-0.379,-0.199)$ & 1.00 \\
LB+ HB 3days & HB 14 days & $-0.01(-0.302,0.276)$ & 1.00 \\
LB+ HB 7days & HB 14 days & $0.08(-0.212,0.366)$ & 1.00 \\
\hline \multicolumn{2}{c}{ Post hoc test (Bonferroni); *statistically significant $p<0.05$}
\end{tabular}

\section{Morphological changes evaluation using SEM.}

SEM analysis revealed that enamel specimens in the control group presented with regular surface morphology, pores and also some superficial irregularities in a certain area. (Figure 1). Effect of bleaching was randomly distributed on enamel surface after combination treatment with morphological changes characterized by waviness, depression, porosities and superficial irregularities of different degree of severity, together with some areas of relatively smooth enamel as seen in Figures 2 and 3. However, morphological surface changes became much more pronounced after HB treatment for 14 days, showing increased depth of irregularities and a number of porosities (Figure 4).

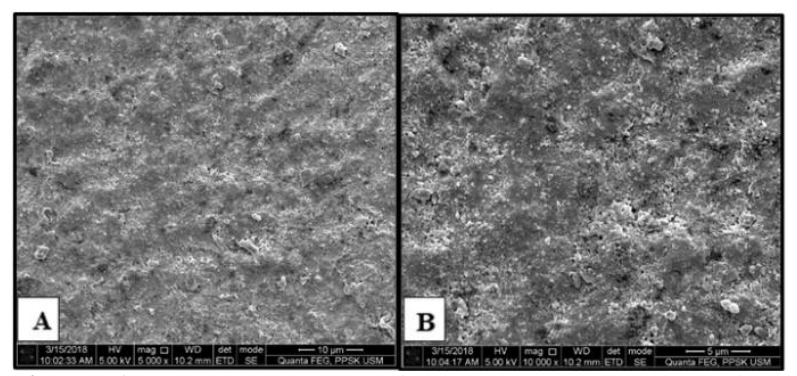

Figure 1: Photomicrograph of the untreated tooth surface. (Magnification: left 5000x; right 10000x)



Figure 2: Photomicrograph of enamel after laser bleaching and home bleaching for 3 days. (Magnification: left 5000x; right 10000x)

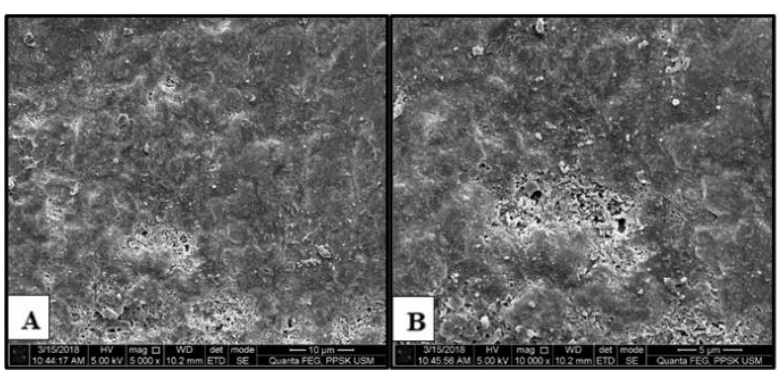

Figure 3: Photomicrograph of enamel after treatment with laser and home bleaching for 7 days (Magnification: left 5000x; right 10000x)



Figure 4: Photomicrograph of altered enamel after home bleaching procedures. (Magnification: left 5000x; right 10000x)

\section{DISCUSSION}

Bleaching has been used for a very long time for patients wanting to have clear bright white teeth. As we know, LB and HB is very commonly used now a days. In our study an interest spiking factor is the use of a combination of the two types of bleaching methods. A combination of these two types of bleaching could not only save chairside time, but could also provide us with satisfactory results within a shorter than expected period of time.

In the current study, the rejected null hypotheses, were as follows: it was seen that there was a significant difference in colour changes of teeth, microhardness of teeth, and in enamel 
surface morphology after treatment with combinations of laser bleaching and different durations of home bleaching protocol. The accepted null hypothesis was that there was no significant difference seen in enamel surface roughness with combinations of laser bleaching and different durations of home bleaching protocol.

In this study, colorimetric analysis was done using spectrophotometer (Vita esay shade guide). A spectrophotometer is an instrument used for measuring the amount of light absorbed by a bleached tooth sample. It helps in determing the "lightness", "chroma" and "hue". ${ }^{26} \mathrm{~L}^{*}$ values represent the lightness or brightness of the samples, whereby low $\mathrm{L}^{*}$ value represent dark or black objects. The highest mean difference in colourimetric assessment for $\mathrm{L}^{*}$ value pre and post bleaching treatment were recorded in group LB + HB 7 days (-31.65). In this study, it was found that $\mathrm{L}^{*}$ values increased significantly in all groups, which implies that teeth in all treatment groups became whiter after bleaching. Thus, all bleaching procedures in this study proved to be effective at whitening as was found in some previous studies. ${ }^{5,27}$ Hence, the null hypthesis was rejected. It is worth noting that, a change in the colour was also found in the control group, nevertheless it was not significant. This result may be due to the storage of control specimens in artificial saliva after staining. Artificial saliva may have washed away the blood or stain molecules. A study by Zeczkowski, M. et $a l^{28}$, (2015) which evaluated the effect of different storage materials on colour variation, also reported a slight increase in $\mathrm{L}^{*}$ value and speculated that it might have occurred because of the constant contact of specimens with saliva. Hence, a minor change that may have occurred in the colour of control group was detected by the spectrophotometer. The $\mathrm{pH}$ value of the solution also plays an important role in the degree of discolouration. ${ }^{29}$ Low $\mathrm{pH}$ is responsible for an increase in tooth staining. While normal blood $\mathrm{pH}$ is tightly regulated between 7.35 and 7.45, to reduce the effect of $\mathrm{pH}$ on the degree of discolouration and to produce close resemblance to the main cause of tooth discolouration, that is intrinsic staining by oxidation of haemoglobin.

However, no significant difference was found between the two combination groups in this study. The objective of LB is to achieve the process by using the most effective energy source while avoiding or reducing the adverse effects. A laser beam activates HP quickly and thus helps in achieving satisfactory whitening of teeth. A study by Son, J. et al, (2012) indicated that diode lasers have a greater penetration depth compared to other laser systems. ${ }^{10}$ Biolase diode laser (Ezlase $810 \mathrm{~nm}$ ) system was used in this study to activate HP, and it was effective in tooth whitening. The results of this study are generally in agreement with other studies on LB, which showed that LB is very efficient. ${ }^{30-32}$ It is believed that $46 \% \mathrm{HP}$ will produce some degree of porosity in the enamel, thus allowing the oxygen free radicals to be trapped in the dental hard tissues for longer periods, eventually facilitating further enhanced bleaching with the application of $\mathrm{CP}$ at home. This explains why combination bleaching protocols were found to be significantly more effective than HB alone.

Changes in organic and inorganic content after bleaching treatment affect the mechanical properties of enamel. Microhardness test is one method used to evaluate these changes in mechanical properties. ${ }^{33}$ In this study, after all bleaching regimens, enamel surface presented with an increase in microhardness $(\mathrm{P}<0.05)$. These results are contradictory with some studies ${ }^{18,19,34-36}$ but are in agreement with

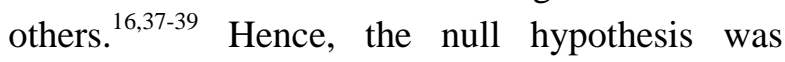
rejected. Determination of loss or gain in mineral contents of enamel after the experiment can be obtained from the differences among the baseline and final microhardness values. A slight reduction in the microhardness in the control group was noted. This is because it was isolated with very low microhardness values and this might be due to the removal of outer hypomineralised enamel layer (often containing fluoroapatite). ${ }^{37}$

Alterations in the mineral content of enamel and dentine are expected to occur during the bleaching procedure due to the acidic properties 
of the materials used. However, mineral content in the enamel may not be affected with the use of bleaching agents that contain fluoride, thus preventing demineralization or loss of enamel..$^{38,40}$ The $0.11 \%$ fluoride ions in the Opalescence PF HB formulation used in the current study, most likely resulted in remineralisation of the enamel. Thus, resulting in maintaining or increasing its microhardness. Hence, post bleaching rehardening of enamel surface was noted in this study which is supported by the use of fluoridated gel as compared to non-fluoridated gels. ${ }^{15,17,20}$

However, another study found a decrease in microhardness of enamel exposed even to a $10 \%$ $\mathrm{CP}$ whitening gel. ${ }^{41}$ Another factor that may attribute to a loss of mineral content is $\mathrm{pH}$ of the bleaching agent. Application of high $\mathrm{pH}$ bleaching agent or phosphoric acid before bleaching procedure may enhance the bleaching effect and cause further microhardness reduction.

Therefore, an increase in the concentration, duration and frequency of exposure of tooth structure to HP, fluoridated bleaching gel, and use of saliva as storage medium play a proportional role on the bleaching action and associated sequelae such as effects on enamel microhardness. Hardness reflects the mechanical properties of natural teeth. ${ }^{19}$ Although no clinical studies or case reports in the literature have documented macroscopically relevant tissue destruction, it is important to minimize the risk of even minor damage to ensure life-long integrity of dental hard tissues. $^{15}$

The key factors that affect tooth whitening efficacy by peroxide-containing agents are its concentration and time. ${ }^{42}$ In this study, surface roughness reduced significantly post-treatment with combination bleaching therapy. However, there was no significant difference between the groups. Hence, the null hypothesis was accepted. Furthermore, in this study, LB +3 days HB significantly reduced the surface roughness compared to the non-treated group. This result is in line with some studies that compared the effect of diode laser activation on the crystalline structure of enamel. ${ }^{10,38,41}$ The study reported that the arrangement of the enamel rods did not break down and was maintained or improved after exposure to laser radiation thus, preventing the roughening of enamel during bleaching. These results lead to the understanding that the damage of tooth structure occurs during the whitening process while using HP. The damage can be significantly reduced or improved by laser exposure and the shorter periods utilized for bleaching treatment. ${ }^{10,41}$ Furthermore, the remineralizing effect exerted by the artificial saliva and fluoride presence enhance the effect. ${ }^{39}$ A study showed that changes in the surface roughness has an increased risk of microbial adhesion to the tooth surface. Thus, this increases susceptibility to the development of caries and staining. ${ }^{43}$

The chromophores existing in the laseractivated gels can absorb the narrow wavelength of diode lasers, thus improving the efficacy of bleaching with lesser heat generation. ${ }^{23}$ It may also be assumed that HP invades into the enamel surface only at the earlier stage and that HP no longer enters into the enamel surface due to the change in property of the whitening gel. ${ }^{10}$ However, these studies ${ }^{10,23,41}$ did not use artificial saliva as a storage medium. As described in previous studies, the opening of diffusion channels on demineralized enamel facilitates diffusion of fluoride and other ions into deeper enamel layers and enhances remineralization near to non-bleached enamel by blocking the surface pores of enamel. All this justifies the results of this study whereby surface roughness was reduced in all treated groups.

Enamel layer of the specimens was etched with $37 \%$ phosphoric acid for 15 seconds to remove the smear layer. Human blood that was obtained from the blood bank was used to stain the specimens like in other studies. ${ }^{7,48}$ Some studies also utilized rat blood for the same purpose. The blood was centrifuged at 10,000 rpm for $10 \mathrm{mins}$ and the serum discarded. Then, $40 \mathrm{~mL}$ of distilled water was added to $60 \mathrm{~mL}$ of the precipitated blood and this mixture was centrifuged at $10,000 \mathrm{rpm}$ for 20 mins like previous studies. ${ }^{7,48}$ 
Thus, in this study professional whitening treatment with HP combined with diode laser irradiation and $\mathrm{HB}$ with $20 \% \mathrm{CP}$ containing fluoride did not alter or reduce enamel surface structure. This demonstrated that simulated intraoral conditions, such as temperature, presence of saliva and shorter bleaching treatment result in different outcomes.

The specimens were evaluated for a variety of surface characteristics. In this study, two specimens from each experimental and control groups were evaluated using SEM. Fragments of each tooth were analyzed by comparing to other groups under 5000x and 10000x magnification. Although the number of samples was considered low to represent each group, SEM analysis was done to support the profilometer readings in this study.

Most investigators have shown that the bleaching agent is able to make changes on enamel surface texture, such as topographical alterations, decalcification and porosities. $^{34,44}$ Nevertheless, in the current investigation, specimens in the control group did not reveal completely smooth enamel surface morphology, showing pores and surface irregularities, similar to another study. ${ }^{45}$ These findings may have resulted due to preparation of samples for microhardness analysis and the variation of the teeth.

In this study, specimens of the bleached group with laser showed relatively smooth enamel surface area, which is in agreement with some studies $^{10,23,30}$ that described a reduction and prevention of loss of mineral compositions in enamel. $^{46}$ Thus, results of this study clearly demonstrate that laser irradiation during the whitening process not only improves the brightness of a tooth but also prevents enamel structure from deformation. Hence, the null hypothesis was rejected.

Within the limitations of this study, it is rather fair to mention, that a larger sample size could have been used and also, since this was an in vitro study, patient cooperation was not required. Further reseach, such as clinical trials should be untertaken in the future to apprehend findings of this study.

\section{CONCLUSIONS}

LB followed by HB for 3 days was found to be the most effective in whitening stained teeth with positive effects on tooth surface microhardness while maintaining surface topography of enamel. Within the limitations of this study, all bleaching protocols tested were effective in whitening discoloured tooth and all groups showed a significant increase in enamel microhardness.

\section{ACKNOWLEDGEMENTS}

Assistance of Mr Yusof Soon Abdullah and Mrs Nora Aziz during laboratory procedures is appreciated. Guidance of Associate Professor Dr. Wan Mohd Amir for statistical analysis and financial assistance from Universiti Sains Malaysia short term grant 304/PPSG/6315195 is acknowledged. Approval from management of Hospital Universiti Sains Malaysia to allow the use of space and assets is appreciated.

\section{CONFLICTS OF INTEREST STATEMENT}

There was no conflict of interest among the authors.

\section{REFERENCES}

1. Zantner C, Schwarzbach NB, Nneumann K. Surface Microhardness of Enamel After Different Home Bleaching Procedures. Journal of Dental Materials. 2007;23:243-250.

2. Neumann L, Christensen C, Cavanaugh C. Dental Esthetic Satisfaction In Adults. Journal Of American Dental Association. 1989;118:565-570.

3. Moraes RR, Marimon JLM, Schneider LFJ. Carbamide Peroxide Bleaching Agents: Effects on Surface Roughness of Enamel, Composite and Porcelain. Clinical Oral Investigation. 2006;10:23-28.

4. Joiner A. The Bleaching of Teeth: A Review of The Literature. Journal of Dentistry. 2006;34:412-419.

5. Jones AH, Diaz-Arnold AM, Vargas MA. Colorimetric Assessment of Laser and Home Bleaching Techniques. Journal of Esthetic Dentistry. 1999;11:87-94. 
6. Joiner A. Review of The Effects of Peroxide on Enamel and Dentine Properties. Journal of Dentistry. 2007;35:889-896.

7. Delfino CS, Chinelatti MA, Carrasco-Guerisoli LD. Effectiveness Of Home Bleaching Agents In Discolored Teeth And Influence On Enamel Microhardness. Journal Of Applied Oral Science. 2009;17(4):284-288.

8. Leonard RH, Haywood VB, Sharma A. Use of Different Concentrations of Carbamide Peroxide for Bleaching Teeth: An in Vitro Study. Journal of Esthetic Dentistry. 1998;29:503-507.

9. Sulieman M, Addy M, Macdonald E, Rees JS. A Safety Study In-Vitro For The Effects Of An In-Office Bleaching System On The Integrity Of Enamel And Dentine. Journal Of Dentistry. 2004;32:581-590.

10. Son JH, An JH, Kim BK. Effect of Laser Irradiation on Crystalline Structure of Enamel Surface During Whitening Treatment With Hydrogen Peroxide. Journal of Dentistry. 2012;40:941-948.

11. Gurgan S, Cakir FY, Yazici E. Different LightActivated In-Office Bleaching Systems: A Clinical Evaluation. Journal of Lasers Medicine Science. 2010;25:817-822.

12. Lima DANL, Aguiar FHB, Liporoni PCS. In Vitro Evaluation of The Effectiveness of Bleaching Agents Activated by Different Light Sources. The American College of Prosthodontists. 2009;18:249-254.

13. Sulieman M. An Overview Of Tooth-Bleaching Techniques: Chemistry, Safety And Efficacy. Periodontology 2000. 2008;48:148-169.

14. Oliveira RD, Paes leme AF, Giannini M. Effect Of A Carbamide Peroxide Bleaching Gel Containing Calcium Or Fluoride On Human Enamel Surface Microhardness. Brazilian Dental Journal 2005;16(2):103-106.

15. Attin T, Betke H, Schippan F. Potential of Fluoridated Carbamide Peroxide Gels to Support Post Bleaching Enamel Rehardening. Journal of Dentistry. 2007;35:755-759.

16. Sasaki RT, Arcanjo AT, Basting RT. Micromorphology And Microhardness Of Enamel After Treatment With Home-Use Bleaching Agents Containing $10 \%$ Carbamide Peroxide And $7.5 \%$
Hydrogen Peroxide. Journal Of Applied Oral Science. 2009;17:611-616.

17. Chen HP, Chang CH, Liu JK. Effect of Fluoride Containing Bleaching Agents on Enamel Surface Properties. Journal of Dentistry. 2008;36:718-725.

18. Hairul Nizam BR, Lima CT, Chng HK, Yap AUJ. Nanoindentation Study of Human Premolars Subjected to Bleaching Agent. Journal of Biomechanics 2005;38: 2204-2211.

19. Attin T, Vollmer D, Wiegand A, Attin R, Betke H. Subsurface Microhardness Of Enamel And Dentin After Different External Bleaching Procedures. American Dental Journal. 2005;18:8-12.

20. Cavalli V, Arrais CAG, Giannini M, Ambrosono GMB. High-Concentrated Carbamide Peroxide Bleaching Agents Effects on Enamel Surface. Journal of Oral Rehabilitation. 2004; 31:155-159.

21.Zanolla J, Marques A, Da Costa DC, De Sauza AS, Coutinho M. Influence Of Tooth Bleaching On Dental Enamel Microhardness: A Systematic Review And Meta- Analysis. Australian Dental Journal. 2016;62(3):276-282.

22. Haywood VB, Leonard RH, Nelson CF, Brunson WD. Effectiveness, Side Effects and Long-term Status of Nightguard Vital Bleaching. Journal American Dental Association. 1994;125:1219-26.

23. Azarbayjani Z, Jafarzadeh Kashi TS, Erfan Y, Chiniforush M, Rakhshan V. Efficacy Of Diode Laser Irradiation During Dental Bleaching In Preventing Enamel Damage Caused By Bleaching. Dental Research Journal. 2018;15:320-6.

24. Pinto CF, Oliveira RD, Cavalli V. Peroxide Bleaching Agent Effects On Enamel Surface Microhardness, Roughness And Morphology. Brazilian Oral Restorative Dentistry. 2004;18(4):306-11.

25. Auschill TM, Hellwig E, Schmidale S, Sculean A. Efficacy, Side-Effects And Patients' Acceptance Of Different Bleaching Technique (Otc, In-Office, AtHome). Journal Of Operative Dentistry. 2005;30(2):156-63.

26. Peskersoy C, Tetik A, Ozturk VO, Gokay N. Spectrophotometric and computerized evaluation of tooth bleaching employing 10 different home- 
bleaching procedures: In-vitro study. European journal of dentistry. 2014;8(4):538.

27. Auschill TM, Hellwig E, Schmidale S, Sculean A. Efficacy, Side-Effects and Patients' Acceptance of Different Bleaching Technique (OTC, In-Office, AtHome). Journal of Operative Dentistry. 2005;30-2:156163.

28. Zeczkowski M, Andalo Tenuta LM, Bovi Ambrosano GM, Baggio Aguiar FH, Nunes Leite Lima DA. Effect of Different Storage Conditions on The Physical Properties of Bleached Enamel: An in Vitro vs. in Situ Study. Journal of Dentistry. 2015;43:11541161.

29. Attin T, Manolakis A, Buchalla W, Hannig C. Influence of Tea on Intrinsic Colour of Previously Bleached Enamel. Journal Oral Rehabilitation. 2003;30(5):488-494.

30. Dostalova T, Jelinkova H, Housova D, Sulc J. Diode Laser-Activated Bleaching. Brazilian Dental Journal. 2004;15:S1-3-S1-8.

31. Luk K, Tam L, Hubert M. Effect of Light Energy on Peroxide Tooth Bleaching. Journal of American Dental Association. 2004;135:194-201.

32. Jelinkova $H$, Dostalova $T$, Nemec $M$. Laser Radiation Tooth Bleaching. Journal of Laser Physics Letters. 2004;1:617-620.

33. Pinto CF, Oliveira RD, Cavalli V. Peroxide Bleaching Agent Effects on Enamel Surface Microhardness, Roughness and Morphology. Brazilian Oral Restorative Dentistry. 2004;18(4):306-611.

34. Oliveira RD, Paes leme AF, Giannini M. Effect of a Carbamide Peroxide Bleaching Gel Containing Calcium or Fluoride on Human Enamel Surface Microhardness. Brazilian Dental Journal 2005;16(2):103-106.

35. Rodrigues JA, Marchi GM, Ambrosano GM, Heymann HO, Pimenta LA. Microhardness Evaluation of In Situ Vital Bleaching on Human Dental Enamel Using A Novel Study Design. Dental Materials. 2005;21(11):1059-1067.

36. Al-Salehi SK, Wood DJ, Hatton PV. The Effect of $24 \mathrm{~h}$ Non-Stop Hydrogen Peroxide Concentration on Bovine Enamel and Dentine Mineral Content and Microhardness. Journal of Dentistry 2007; 35:845-850.
37. Basting RT, Rodrigues Junior AL, Serra MC. The Effects Of Seven Carbamide Peroxide Bleaching Agents On Enamel Microhardness Over Time. Journal American Dental Association. 2003;134:1335-1342.

38. Faraoni JJ, Silveira AGD, Turssi CP, Serra MC. Bleaching Agents with Varying Concentration of Carbamide and/or Hydrogen Peroxides: Effect on Dental Microharness and Roughness. Journal Compilation. 2008;20(6):395-402.

39. Delfino CS, Chinelatti MA, Carrasco-Guerisoli LD. Effectiveness of Home Bleaching Agents in Discolored Teeth and Influence on Enamel Microhardness. Journal of Applied Oral Science. 2009;17(4):284-288.

40. Marcondes M, Paranhos MPG, Sspohr AM. The Influence of the Nd:YAG Laser Bleaching on Physical and Mechanical Properties of the Dental Enamel. Journal of Biomedical Materials Research Part B: Applied Biomaterials. 2008:388-396.

41. Mirzaie M, Yassini E, Ganji S, Moradi Z, Chiniforush M. A Comparative Study of Enamel Surface Roughness After Bleaching With Diode Laser and Nd: YAG Laser. Journal of Lasers in Medical Sciences. 2016;7(3):197-200.

42. Wetter NU, Barosso MC, Pelino JE. Dental Bleaching Efficacy With A Diode Laser and LED Radiation. Lasers in Surgery and Medicine. 2004;35:254-258.

43. Hosoya N, Honda K, Lino F, Arai T. Changes In Enamel Surface Roughness And Adhesion Of Streptococcus Mutans To Enamel After Vital Bleaching. Jornal Of Dentistry. 2003;31:543-548.

44. Bitter NC, Sanders JL. The Effect Of Four Bleaching Agents On The Enamel Surface: A Scanning Electron Microscopy Study. Quintessence International. 1993;24:817-824.

45. Ferreira SDA, Aarau' jo JLN, Morhy ON. The Effect of Fluoride Therapies on the Morphology of Bleached Human Dental Enamel. Journal of Microscopy Research and Technique 2011;74:512-516

46. Hegedu“s C, Bisteya T, Flo'ra-Nagya E, Keszthelyia G, Jeneib A. An Atomic Force Microscopy Study On The Effect Of Bleaching Agents On Enamel Surface. Journal of Dentistry. 1999;27:509-515. 
47. Pop-Ciutrila, Ioana-Sofia, Horatiu Alexandru Colosi, Diana Dudea, and Mandra Eugenia Badea. "Spectrophotometric Color Evaluation Of Permanent Incisors, Canines And Molars. A Cross-Sectional Clinical Study." Clujul Medical 88, No. 4 (2015): 537.

48. Freccia, William F., and Donald D. Peters. A Technique For Staining Extracted Teeth: A Research
And Teaching Aid For Bleaching. Army Inst Of Dental Research Washington DC, 1980.

49. Ahmad, Irfan. "Digital dental photography. Part 7: extra-oral set-ups." British dental journal 207, no. 3 (2009): 103-110. 